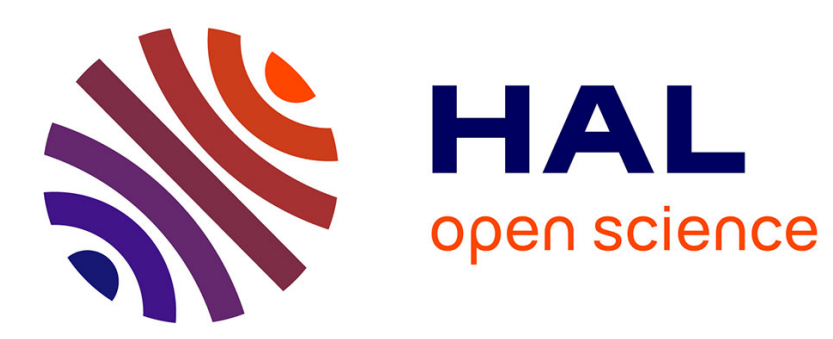

\title{
Microemulsions for oral administration and their therapeutic applications.
}

Stéphane Gibaud, David Attivi

\section{To cite this version:}

Stéphane Gibaud, David Attivi. Microemulsions for oral administration and their therapeutic applications.. Expert Opinion on Drug Delivery, 2012, 9 (8), epub ahead of print. 10.1517/17425247.2012.694865 . hal-00706176

\section{HAL Id: hal-00706176 \\ https://hal.science/hal-00706176}

Submitted on 14 Jun 2015

HAL is a multi-disciplinary open access archive for the deposit and dissemination of scientific research documents, whether they are published or not. The documents may come from teaching and research institutions in France or abroad, or from public or private research centers.
L'archive ouverte pluridisciplinaire HAL, est destinée au dépôt et à la diffusion de documents scientifiques de niveau recherche, publiés ou non, émanant des établissements d'enseignement et de recherche français ou étrangers, des laboratoires publics ou privés. 


\title{
Microemulsions for oral administration and their therapeutic applications
}

\author{
Stéphane GIBAUD ${ }^{1,2}$, - David ATTIVI ${ }^{2}$ \\ 1 : Université de Lorraine - CITHEFOR, EA 3452 - 5, rue Albert Lebrun (Faculté de pharmacie) - F-54000 Nancy - France \\ 2 : Centre Hospitalier de Neufchâteau - 1280, avenue de la division Leclerc - 88300 Neufchâteau - France
}

Corresponding author :

Dr. Stéphane GIBAUD , PhD, PharmD

Université de Lorraine

CITHEFOR, EA 3452

5 , rue Albert Lebrun (Faculté de pharmacie)

F-54000 Nancy - France

email : stephane.gibaud@univ-lorraine.fr

Orther author :

Dr. David ATTIVI, PhD PharmD

Hospital Pharmacist

1280, avenue de la division Leclerc

88300 Neufchâteau

France

Email : d.attivi@ch-neufchâteau.fr 
1. INTRODUCTION

\section{Content}

2. FORMULATION OF S(M)EDDS

2.1. Oils and surfactants

2.2. Pseudoternary diagrams

2.3. Physicochemical assessment

2.3.1. Transparency

2.3.2. Stability

2.3.3. Conductivity

2.3.4. Droplet size determination

2.3.5. Zeta potential measurement

2.3.6. Viscosity

3. ORAL ABSORPTION OF MICROEMULSIONS

4. IN VITRO METHODS FOR INTESTINAL ABSORPTION ASSESSMENT

4.1. Caco-2 and other "intestinal-like" cell lines

4.2. Parallel artificial membrane permeability assay (PAMPA)

4.3. Everted sac and ussing chamber

4.4. In situ rat intestinal perfusion

5. APPLICATIONS

5.1. $S(M) E D D S$ of cyclosporine (Neoral, Gengraf $\circledast$ )

5.2. $S(M)$ EDDS of antiviral drug (Fortovase ${ }^{\circledR}$, Norvir ${ }^{\circledR}$ )

5.3. $S(M) E D D S$ of statins (not marketed)

5.4. S(M)EDDS of anticancer drug (not marketed)

5.4.1. Paclitaxel

5.4.2. Mitotane

5.5. $\quad S(M) E D D S$ of antibiotics (not marketed)

5.6. Other S(M)EDDS (not marketed)

6. COMPARISON WITH OTHER DRUG DELIVERY SYSTEMS

7. CONCLUSION

8. EXPERT OPINION 


\section{Microemulsions for oral administration and their therapeutic applications}

\section{Abstract}

Introduction: The microemulsion concept was introduced in 1943 by Hoar and Schulman. Self-microemulsifying drug delivery systems [S(M)EDDS] are much more recent and can be described as isotropic solutions of oils and surfactants that form oil-in-water O/W microemulsions when they are poured into an aqueous medium. When they are presented as soft capsules for oral delivery, S(M)EDDS have the ability to considerably improve the intestinal absorption of agents that are incorporated into the S(M)EDDS. Forty per cent of newly discovered drug candidates have little or no water solubility and therefore have low and/or variable bioavailability profiles. Many of these drugs are good candidates for formulation into S(M)EDDS.

Areas covered: This paper describes the preparation and assessment of these formulations and their current applications. The characterisation of this type of formulation has improved, and in vitro models (Caco-2 cell cultures, Ussing chambers, the everted sac technique, etc.) can be used for screening different formulations. It describes also marketed formulations [i.e., cyclosporine and saquinavir S(M)EDDS] and somes other formulations.

Expert opinion: Actual applications of S(M)EDDS remain rare. The first drug marketed as a S(M)EDDS was cyclosporine, and it had significantly improved bioavailability compared with the conventional solution. In the last decade, several S(M)EDDS loaded with antiviral drugs (e.g., ritonavir, saquinavir) were tested for treatment of HIV infection, but the relative improvement in clinical benefit was not significant. The S(M)EDDS formulation of Norvir $^{\circledR}$ (soft capsules) has been withdrawn in some countries.

\section{Keywords:}

Microemulsion - Nanoemulsion - Self-emulsifying system - Bioavailability 


\section{Introduction}

Microemulsions are the result of nearly sixty years of research, starting when Hoar and Schulman first introduced the microemulsion concept in 1943 after they mixed a milky solution with hexanol [1] to obtain a clear, single-phase and non-conducting solution. They defined the term "microemulsion" as an optically isotropic and transparent oil and water $(\mathrm{O} / \mathrm{W})$ dispersion consisting of approximately equal volumes of the two phases. Furthermore, the O/W dispersion contained droplets of either water or oil in the appropriate continuous phase, with the droplets having diameters that were somewhat greater than the diameter of swollen micelles [2].

In 1981, microemulsions [3] were defined as systems of water, oil and amphiphile that were single optically isotropic and thermodynamically stable liquid solutions. No indication of size was stated but the size of particles was typically between 5 and $100 \mathrm{~nm}[4]$.

Shafiq et al. [5] have noticed that the word microemulsion was often a misnomer and should not be used for droplets with diameters of less than $100 \mathrm{~nm}$. This limit size is often cited in nanotechnology regulatory publications. In fact, for this type formulation, the term "nanoemulsion" should be used for non-equilibrium systems that over time spontaneously will exhibit coalescence of the dispersed droplets [6], whereas microemulsions are thermodynamically stable.

In 2012, the term "microemulsion" is still used for systems with droplets < $100 \mathrm{~nm}$ [7] [8] and "nanoemulsion" is sometimes used for globule size $>100 \mathrm{~nm}$ [9].

The confusion is due to the fact that both self-microemulsifying systems (SMEDDS) and self-nanoemulsifying systems (SNEDDS) form dispersions with an emulsion particle size in the nanometre range [6]. In this review, these formulations are called "S(M)EDDS".

Among lipid formulations, self-microemulsifying drug delivery systems [S(M)EDDS] are very specific. They are isotropic solutions of oils and surfactants that form O/W microemulsions when they are poured into an aqueous medium. Very gentle agitation allows dispersion of the isotropic solution into the aqueous medium. S(M)EDDS allow the drug to absorb without being digested, and they are classified 
as Type III formulations using the lipid formulation classification system developed by C.W. Pouton $[10 ; 11]$.

S(M)EDDS are administered by the oral route and represent an area of major interest for the clinical use of lipophilic compounds. Gastric and intestinal motility in vivo produce an agitation that is able to create an emulsion, and the resultant fine droplets provide a large surface area and facilitate good absorption. S(M)EDDS formulations are administered in soft gelatin capsules and are convenient for the patient.

\section{Formulation of S(M)EDDS}

\subsection{Oils and surfactants}

Surfactants are preferably non-ionic compounds that have low toxicity. The surfactants that have been used for the preparation of S(M)EDDS are detailed in Table 1.

Hydrophilic surfactants are most commonly selected for the preparation of microemulsions. These surfactants are obtained from reactions between polyethyleneglycol and vegetable oils and they have HLB (Hydrophilic-Lipophilic Balance) values equal to or greater than 12. Cremophor $^{\circledR}$ derivatives (type EL or RH 40) are frequently used in the pharmaceutical industry.

Cremophor $^{\circledR}$ has been shown to inhibit P-glycoprotein. This glycoprotein favours the efflux of xenobiotic compounds with broad substrate specificity, and it is responsible of the efflux of xenobiotic and toxic metabolites from cells into the bile or urine. Cremophor ${ }^{\circledR}$ was proposed to have an impact on multidrug resistance through limitation of the efflux of therapeutic agents from cancer cells. However, the concentration of this surfactant attained in vivo in solid tumours [20] is probably not sufficient to affect multidrug resistance. More recently, similar phenomena have been described for various other non-ionic surfactants, including Tween 80 [21], Solutol HS 15 [22] and Triton X-100 [23].

More lipophilic surfactants can also be used for O/W microemulsions. A particularly important class of surfactants consists of mono- and diglycerides such as glyceryl caprylatelcaprate (Capmul ${ }^{\circledR}$ MCM) or glyceryl monooleate (Maisine ${ }^{\circledR} 35-1$, Peceol ${ }^{\circledR}$ ). 
These compounds are not soluble in water. They can improve the solubility of the drug and act as co-surfactants $\left(\right.$ Transcutol $^{\circledR}$, Peceol $^{\circledR}$ ).

Oils can be classified as long chain triglycerides (LCT) and medium chain triglycerides (MCT). MCT have been preferred due to their higher fluidity, better solubility and self-emulsification ability relative to LCT [24; 25]. The chemical structure of MCT (i.e., the lack of double bonds) protects them from oxidation and allows them to be isolated in higher purity. MCT and LCT are differentially absorbed into the body: LCT are transported into the intestinal lymphatic vessels, whereas MCT are directly transported into the portal blood vessel [26]. However, these differences only lead to minor differences in oral bioavailability [27].

Short chain alcohols are usually used in conjunction with surfactants to stabilise microemulsions [28; 29].

\subsection{Pseudoternary diagrams}

The formulation of microemulsions necessitates the study of pseudo-ternary diagrams (water/amphiphile/oil) or quaternary diagrams (water/surfactant/cosurfactant/oil). In practice, one can observe whether a microemulsion forms immediately upon mixing of the oily phase, the surfactants and the aqueous medium. Titration is a simple method to determine the microemulsion region (Figure 2): mixtures of oil and surfactants are titrated with water in a dropwise manner and

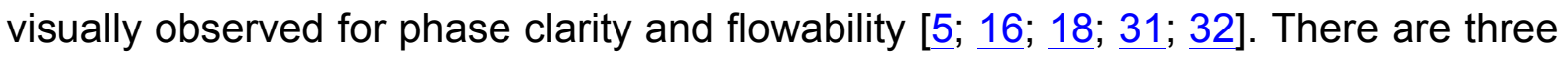
different structural types of microemulsions: water-in-oil (W/O), oil-in-water (O/W) and bicontinuous structures. The distinctions between these structural types are important in the assessment of microemulsions, and further characterisation of these parameters (e.g., size, type of emulsion) is warranted.

\subsection{Physicochemical assessment}

\subsubsection{Transparency}

By definition, a microemulsion is transparent, but this term needs to be quantified if perfect transparency is not required. A Tyndall effect can be observed and suggests 
that the particle diameters are on the order of $1 / 4$ the wavelength of the incident light [33]. As described previously, microemulsions can be translucent solutions with a slight sky-blue opalescence [34].

An assessment of transparency is commonly used to define the microemulsion zone in pseudo-ternary diagrams. Nepheloturbidimetric evaluation can be performed to monitor the growth of droplets in microemulsions. Fixed quantity of S(M)EDDS is added to fixed quantity of suitable medium under continuous stirring (50 rpm) on magnetic plate at ambient temperature. In turbidimetry, the intensity of light transmitted through the medium, the unscattered light, is measured. In nephelometry, the intensity of the scattered light is measured, usually, but not necessarily, at right angles to the incident light beam.

\subsubsection{Stability}

The stability of emulsions is usually assessed for each different formulation. Poor physical stability of a formulation can lead to phase separation of the excipient and impact the visual appearance of the preparation. In addition, physical instability can be caused by precipitation of the drug from the oily matrix. Testing methods [18] such as heating-cooling cycling, centrifugation and freeze-thaw cycling can be used to assess the physical stability of microemulsions [35].

Microemulsions are stabilised by the surfactants, and the formation of the droplets depends on the elastic properties of the surfactant film at the $\mathrm{O} / \mathrm{W}$ interface. Two critical parameters are the curvature and the rigidity of the film [36] .

Calculations of the interfacial tension [37] of the microemulsion with a coexisting oil or aqueous phase may sometimes be used as a guide for their formulation [38; 39].

\subsubsection{Conductivity}

Conductivity measurements are currently carried out to determine the makeup of the continuous phase: O/W emulsions are conductive, whereas W/O emulsions are nonconductive.

Chen et al.[40] have studied the variations of conductivity during titration and have concluded that this method can be used to screen formulations. Various types of conductivity meters can be used. 


\subsubsection{Droplet size determination}

Size determination of droplets is very useful in evaluations of stability. Size is currently measured by photon correlation spectroscopy (PCS) with a Zetamaster [41]. The samples are usually prepared by diluting the S(M)EDDS 1:5 with the external aqueous phase, followed by filtration through $0.45 \mu \mathrm{m}$ filters prior to analysis. All measurements are carried out at a scattering angle of $90^{\circ}$ and at $25^{\circ} \mathrm{C}$.

\subsubsection{Zeta potential measurement}

Gershanik et al. introduced the measurement of the Zeta potential for the characterisation of S(M)EDDS [42]. This measurement is based on the fact that the positively charged oil droplets formed by S(M)EDDS dilutions can elicit a strong interaction with the mucosal surface. The intestinal interior is negatively charged relative to mucosal fluid, which can improve the uptake of the drug.

The Zeta potential is currently determined by the measurement of electrophoretic mobility. The technique used to measure this velocity in Malvern's Zetasizer Nano series of instruments (Malvern Instruments, Worcestershire, UK) is Laser Doppler Velocimetry (LDV) also known as Laser Doppler Velocimetry (LDA) [17; 43; 44].

\subsubsection{Viscosity}

The structure and type of microemulsion system can be characterised by rheological measurements as a function of the aqueous phase. If system has low viscosity then it is O/W type. If system has high viscosity, then it is W/O type. For example, the viscosity of lovastatin [lovastatin $(20 \mathrm{mg})$, Capmul ${ }^{\circledR}$ MCM $(7 \%)$, Cremophor $®$ EL (24\%), Transcutol® P (8\%)] increased from $53.66 \mathrm{cP}$ to $75.40 \mathrm{cP}$, with increasing water content between $0-30 \%$, which then gradually decreased beyond $30 \%$ [43]. This may be due to the fact that the system transforms from W/O (when [water] > $30 \%)$ through bicontinuous structure $(40 \%<$ [water] $<70 \%)$ to O/W system.

Moreover S(M)EDDS are generally administered in soft gelatin or hard gelatin capsules and it should be easily pourable into capsules and such system should not be too thick.

There are a variety of in-line viscometers, which can be used to measure the viscosity of an emulsion. However, pressure gradient-based viscosimeters, coaxial 
cylinder viscosimeters and vibrating-element viscosimeters are more popular in the industry [45].

\section{Oral absorption of microemulsions}

It has been reported that S(M)EDDS-type O/W microemulsions can increase the solubility of compounds by dissolving poorly soluble compounds into the oil phase, thereby enhancing oral bioavailability. S(M)EDDS can also enable stable gastrointestinal absorption by limiting the influence of the flow of bile secretions [46].

The lipids included in the formulations (MCT or LCT) are transported in the body in different ways: MCT are directly transported into the portal blood vessel and from there into the systemic circulation, whereas LCT are transported into the intestinal lymphatics [26]. However, these differences only lead to minor differences in oral bioavailability. A comparison of MC-S(M)EDDS [S(M)EDDS made with MCT] and LC-S(M)EDDS [S(M)EDDS made with LCT] was performed by Grove et al. [27]. The results indicate that, despite the difference in nature of the lipids, the processes of dispersion and distribution resulted in the equivalent bioavailability of the drug (i.e., seocalcitol), which supported the hypothesis that an equal solubilising capacity was effective in vivo.

Surfactants have an influence on the absorption of drugs. For example, the surface areas of cells exposed to Tween 60 are increased by greater than a factor of two [47]. This increase probably was the result of a flattening of the undulated membranes during swelling caused by the opening of microtubules leading to the cell surface.

Many papers have hypothesised that incorporated drugs are released in the mucin layer, without an intermediate step of mixed micelle formation by bile, prior to the drug permeating the intestinal membrane [46] (Figure 1). 


\section{In vitro methods for intestinal absorption assessment}

Many of the in vitro methods for intestinal absorption assessment have been described. These methods include the use of artificial membranes, Ussing chambers, Caco-2 monolayers and in situ rat intestinal perfusion. None of the methods includes all the absorption processes that have been proposed for in vivo absorption.

\subsection{Caco-2 and other "intestinal-like" cell lines}

Caco-2 and other "intestinal-like" cell lines (MDCK, TC-7, HT29-MTX, 2/4/A1) enable mechanistic studies and help to identify drug-drug interactions at the level of PgP.

Caco 2 screens were frequently performed to compare the absorption of drugs with different formulations and, in particular, microemulsion formulations [14; 16; 48-50]. This method must be used cautiously and account for the direct toxicity of surfactants. Moreover, some surfactants can modify absorption and/or cell transport. For example, at low concentrations $(0.1 \%$ and $1 \%)$, Labrasol ${ }^{\circledR}$ could open tight junctions [51]; whereas at higher concentrations (33\%) it could inhibit intestinal cell transporters.

\subsection{Parallel artificial membrane permeability assay (PAMPA)}

The parallel artificial membrane permeability assay (PAMPA) is extensively used for the evaluation of drug candidates and is amenable to automation. It is especially useful in assessing transmembrane, non-energy dependent diffusion of drug formulations [52].

These artificial membranes have been prepared by impregnating a porous filter with a solution of lipid mixture (i.e., a mixture of lecithin and an inert organic solvent).

[53]. The assay now provides good predictability for many compounds, but the early methods suffered several shortcomings, including reproducibility, stability, mass retention and the incorrect prediction for a group of highly permeable compounds that included caffeine and antipyrine [54]. More recently, Araya et al. have tested microemulsions with PAMPA and have observed very low diffusion rates compared with another model (i.e., the Ussing chamber). This discrepancy was attributed primarily to the absence of a mucin layer [46]. We believe that biological models are required to mimic the in vivo environment. 


\subsection{Everted sac and Ussing chamber}

The everted sac and Ussing chamber techniques are more advanced models than PAMPA in that they can provide additional information with respect to intestinal metabolism.

Ussing chambers have been used to study the influence of the bile and of the mucus. It has been reported that the drug incorporated into an $\mathrm{O} / \mathrm{W}$ microemulsion (i.e., ibuprofen) was released in the mucin layer, without passing through an intermediate step of mixed micelle formation by bile, thereafter permeating the intestinal membrane. [46].

The Ussing chamber method has been used to compare the absorption of $\mathrm{O} / \mathrm{W}$ microemulsions of mitotane with crystals of mitotane [16]. However, the results of the Ussing test indicated that this comparison would require in vivo testing.

\subsection{In situ rat intestinal perfusion}

The in situ rat intestinal perfusion model is a reliable technique to investigate drug absorption potential in combination with intestinal metabolism. However, it is time consuming and therefore not suited for screening purposes.

In vivo absorption in animals can be estimated from bioavailability studies using the ratio of the plasma AUC after oral and i.v. administration. The impact of liver metabolism on bioavailability can be evaluated by sampling at the portal vein.

All of these methods can be used to assess the permeation of microemulsions through the GI tract but, because there is no bile or mucus included in these methods, these experiments have to be followed up with in vivo pharmacokinetic studies. 


\section{Applications}

\section{1. $S(M) E D D S$ of Cyclosporine (Neoral, Gengraf ${ }^{\circledR}$ )}

Cyclosporine is a cyclic undecapeptide with immunosuppressive activity. It has dramatically improved the prevention of transplant rejection [55]. When given orally, cyclosporine is poorly absorbed, and only approximately $30 \%$ of the drug reaches the systemic circulation [56-58]. Moreover, the absorption is highly variable and is affected by physiological factors (i.e., bile flow, fatty foods) [59; 60].

Cyclosporine is only absorbed in the upper part of the Gl tract and needs to be dissolved in bile for absorption to occur [61]. This requirement creates intra- and interpatient variability [62] and difficulties in patients undergoing liver transplants [63]. The first attempts to optimise the oral delivery of cyclosporine formulations led to the development of an oily solution containing olive oil [64]. A few years later, the formulation was modified by the use of maize oil in soft gelatin capsules $\left(\right.$ Sandimmun $^{\circledR}$ ). This formulation was more convenient, but the absorption was still highly variable, especially in the postoperative period after liver transplantation. In these situations, patients with an external biliary diversion failed to absorb the conventional oral cyclosporine solution Sandimmun® (Figure 3) [61]. Cyclosporine administration in these cases required much more toxic parenteral infusions to reach stable therapeutic concentrations, and the patients had to stay hospitalised [63].

The first S(M)EDDS that were marketed were cyclosporine preconcentrates (i.e., Neoral ${ }^{\circledR}$, Neoral Sandimmun ${ }^{\circledR}$ and Sandimmun Neoral ${ }^{\circledR}$, Table 2) [65]. Cyclosporine is a very lipophilic compound and was ideally suited for this kind of formulation. Gengraf $\circledast$ is now marketed in some countries and can be considered bioequivalent to Neoral@.

The microemulsion formulation of cyclosporine shows a particular improvement in the pharmacokinetic profile. It provides reduced inter- and intraindividual variability, as well as a more predictable and consistent concentration-time profile. In 1994, Mueller et al. compared $\mathrm{Neoral}^{\circledR}$ to Sandimmune Neoral ${ }^{\circledR}$ on 24 healthy male volunteers receiving each formulation on 2 separate occasions. The reference treatment was a single oral dose of $300 \mathrm{mg}$ of Sandimmune ${ }^{\circledR}$ and the test treatment was a single oral dose of $180 \mathrm{mg}$ of Sandimmune Neoral ${ }^{\circledR}$ [62]. 
Another study was done on 48 healthy volunteers receiving a single oral administration (Sandimmune ${ }^{\circledR}$ vs. Sandimmune Neoral ${ }^{\circledR}$ ) $[66 ; 67]$. In comparison to Sandimmune ${ }^{\circledR}$, the maximum concentration $\left(\mathrm{C}_{\max }\right)$ and $\mathrm{AUC}$ of cyclosporine were greater for Sandimmune Neoral $^{\circledR}$ at all dose levels investigated. The relative bioavailability of cyclosporine from Sandimmune Neoral ${ }^{\circledR}$ ranged from 174 to $239 \%$ compared to Sandimmune ${ }^{\circledR}$, depending on the dose level. This formulation yielded a stronger correlation between concentration and systemic exposure (AUC) compared with Sandimmune ${ }^{\circledR}[67]$.

In the setting of postoperative liver transplantation, Trull et al. have demonstrated that the microemulsion has bioavailability 8.5-fold greater than the conventional solution (4.0 vs. $0.47 \%$ ). These findings enabled the use of S(M)EDDS formulations (10 mg/kg daily) instead of infusions [63] and resulted in reduced side effects and accelerated discharge from hospital.

In kidney transplant patients treated with microemulsions of cyclosporine, blood concentrations of cyclosporine were more stable and strongly correlated with systemic exposure. Kovarik et al. compared the administration of the commercial solution (Sandimmune ${ }^{\circledR}$ ) with the microemulsion formulation over a 24-h period [62; 66]. The study was done on 11 stable renal transplant patients receiving 1 soft capsule/12 $\mathrm{h}$ and the authors compared the daytime fasting period and the nighttime nonfasting period. For the commercial formulation, there was considerable variation in absorption rate. By contrast, the microemulsion exhibited a more stable fluctuation. In these cases, S(M)EDDS formulations delivered orally had reduced nephrotoxicity compared with infused cyclosporine.

\section{2. $S(M) E D D S$ of antiviral drug (Fortovase ${ }^{\circledR}$, Norvir $^{\circledR}$ )}

The development of HIV protease inhibitors (PI) has been a significant advancement in the control of HIV infection. Unfortunately, these compounds are very lipophilic, have poor water solubility, undergo extensive first-pass metabolism and exhibit poor oral bioavailability [68]. 
Two formulations of antiviral drugs are now marketed for the treatment of HIV infection: Fortovase ${ }^{\circledR}$ (saquinavir) and Norvir $^{\circledR}$ (ritonavir). The formulation of saquinavir is a mixture of medium chain mono- and diglycerides, povidone and $\alpha$ tocopherol (Fortovase $®$ ). It was also called EOF (enhanced oral formulation) of saquinavir. The inclusion of Vitamin $E$ is of note as it is one of the recommended supplements for HIV patients [69]. Vitamin E helps boost the immune system and protects the cell membranes. Recently, antioxidants used as surfactants and cosurfactants (i.e., Vitamin C, Vitamin E, ethyl linoleate and oleic acid) have been shown to reduce gastrointestinal side effects. The relative bioavailability of drug from a microemulsion containing Labrafac $^{\circledR}$ CM10 (4.0\%), Tween 80 (36.0\%), polyethylene glycol $400(9.0 \%)$ and distilled water (51\%) was found to be $57.68 \%$, which is 10.68 times higher than that of the commercially available tablets [70]. Fortovase ${ }^{\circledR}$ capsules (saquinavir EOF) and Invirase ${ }^{\circledR}$ (saquinavir mesylate) capsules are not bioequivalent and cannot be used interchangeably. When using saquinavir as a sole protease inhibitor in an antiviral regimen, Fortovase ${ }^{\circledR}$ is the recommended formulation. Invirase ${ }^{\circledR}$ may be considered only if it is combined with ritonavir, which significantly inhibits the metabolism of saquinavir to provide plasma saquinavir levels at least equal to those achieved with Fortovase ${ }^{\circledR}$ at the recommended dose of 1200 mg twice in day (18 soft capsules of Fortovase ${ }^{\circledR} /$ day).

However, plasma concentrations obtained with Fortovase ${ }^{\circledR}$ may still be lower than expected and insufficient for good antiviral efficacy. The only established method to reach adequate saquinavir concentrations is by combining saquinavir with ritonavir [71]. Surprisingly, saquinavir (Fortovase ${ }^{\circledR}$ ) exposure was improved by fatty meals (Figure 4). Moreover, the administration of 18 soft capsules is not convenient for the patient.

For ritonavir S(M)EDDS, the mixture is comprised of butylated hydroxytoluene, ethanol, oleic acid and polyoxyl 35 castor oil. A significant improvement in the bioavailability of ritonavir of up to $331 \%$ compared with hard gelatin capsules was shown [72].

Ritonavir ${ }^{\circledR}$ soft capsules must be stored between $2^{\circ} \mathrm{C}$ and $8^{\circ} \mathrm{C}$. The capsule format has been replaced by tablets in several countries. 
Other antiviral drugs have been formulated as S(M)EDDS (e.g. UC781anti-HIV [73] and acyclovir [74]) but have not led to marketed products.

\section{3. $S(M) E D D S$ of statins (not marketed)}

The development S(M)EDDS containing statins is a very attractive idea because droplets are absorbed following a process similar to that observed with cholesterol from food (i.e., chylomicrons).

The lipophilicity of these compounds is quite important and influences the solubility and the absorption, the latter varying from 30 to $98 \%$. All statins undergo hepatic first-pass metabolism that accounts for their low systemic bioavailabilities. Statins undergo extensive microsomal metabolism by the cytochrome P450 (CYP) isoenzyme system, with the exception of pravastatin, which is transformed enzymatically in the liver cytosol.

In fact, statins (i.e., simvastatin and lovastatin) were selected as a model class of compounds characterised by low bioavailability (i.e., approximately $5 \%$ ) for the development of S(M)EDDS [31; 43]. This low bioavailability is due primarily to firstpass metabolism but also to low absorption..

Two formulations of S(M)EDDS including simvastatin have been prepared and assessed by Kang et al. [31]. Both formulations resulted in a 1.5-fold increase in bioavailability that correlated to complete absorption (approximately 100\%).

Recently, S(M)EDDS of lovastatin have been prepared and revealed a more pronounced increase in bioavailability of lovastatin (4.7-fold). Again, this improvement could be due to complete absorption of the drug, but an effect on the first-pass metabolism cannot be excluded.

Atorvastin, another HMG CoA inhibitor, has been used for the preparation of S(M)EDDS. This drug has an absolute bioavailability of $14 \%$ and a systemic availability of HMG-Co A reductase inhibitory activity of approximately $30 \%$. Food decreases the rate and the extent of drug absorption by approximately $25 \%\left(C_{\max }\right.$ and AUC) [75]. 


\subsection{S(M)EDDS of anticancer drug (not marketed)}

Oral anticancer drugs have been available since the early days of cancer treatment. Among other reasons, their use had been limited due to their unpredictable oral bioavailability, resulting in a preference for intravenous agents. S(M)EDDS may correct this drawback, and many formulations have been proposed [32] [34; 76-78].

\subsubsection{Paclitaxel}

Paclitaxel, an alkaloid extracted from the bark of the Pacific yew tree Taxus brevifolia, is a major anticancer drug active against breast cancer [79], ovarian cancer [80], non-small lung [81] cancer and head and neck cancer [82]. The compound is insoluble in water and has been formulated as a mixture of ethanol and polyoxyethylated castor oil (Cremophor EL), with the latter excipient being responsible for drug-related hypersensitivity reactions [20]. Many attempts have been made to obtain a Cremophorß-free formulation. Recently, nanoparticle albumin-bound paclitaxel (Abraxane ${ }^{\circledR}$ ) provided better solubility and enhanced uptake of drug into solid tumours [83].

Oral formulations may overcome the hypersensitivity reaction resulting from systemic administration of Cremophor ${ }^{\circledR}$ EL [17]. The oral route of administration has other potential advantages including less-frequent outpatient visits and easier chronic administration. Although yew capsules are available in different countries as supplements, the major compounds (i.e., taxanes) are known to be poorly absorbed. Many researchers have proposed oral formulations of paclitaxel with better bioavailability $[34 ;$ 76-78]. The nanoemulsion proposed by Shandavilli et al. has increased oral bioavailability to greater than $70 \%$ [84].

\subsubsection{Mitotane}

Mitotane is an organochloride derivative (insecticide) and is insoluble in water. In 1949, researchers working on insecticide compounds reported that the 
administration of DDD (diphenyldiphenyldicloroethane) led to an atrophy of adrenocortical tissue.

A few years later, Nichols demonstrated that the major active compound was o,p'DDD (o,p'-dichlorodiphenyldichloroethane, mitotane), an isomer of DDD [85].

In humans, the first use of mitotane was in the treatment of Cushing's syndrome caused by bilateral adrenocortical hyperplasia [86]. This work marked the start of a series of clinical trials. The first formulations consisted of rough powder or lipidic emulsions. The dosages were inaccurate and it was very difficult to reach the targeted concentration of drug. Serum drug levels were higher when the drug was given in vehicles such as tablets, milk, chocolate, or an emulsion.

Tablets of mitotane comprised of $500 \mathrm{mg}$ of o,p'-DDD and polyethylene glycol are marketed by HRA Pharma in Europe [87]. The target concentrations can be reached only after 3-5 months with a total dose of $363 \mathrm{~g}$ (6 tablets daily for 4 months).

Recently, S(M)EDDS formulations of mitotane have been developed [16] and tested in dogs [88]. The improvement in the bioavailability of drug was 4,7-fold, but the number of capsules/day required was still too high to permit marketing of the product.

\subsection{S(M)EDDS of antibiotics (not marketed)}

Although some hydrophilic antibiotics (e.g., aminoglycosides, glycopeptides, and colistin) cannot be absorbed orally, others, such as the $\beta$-lactam antibiotics, are susceptible to hydrolysis. For example, Cefpodoxime proxetil (CPF) is a thirdgeneration cephalosporin ester indicated for urinary tract and upper respiratory tract infections. Its low bioavailability (approximately 50\%) can be attributed to the degradation of its ester side chain by cholinesterase in the intestinal lumen. S(M)EDDS have been proposed to improve the pharmacokinetic parameters of CPF[9]. However, other studies have demonstrated that $\beta$-lactam antibiotics cannot be protected by inclusion in a colloidal delivery system [89].

Solid dispersions and microemulsions of ketoconazole were prepared by Heo [90] with good improvement in bioavailability $(6,92$-fold). Oral formats of this drug were withdrawn from the market in many countries due to the association of ketoconazole with hepatic toxicity, including some fatalities. 
Berberine, a quaternary ammonium salt used as a traditional medicine and dietary supplement, has shown some activity against fungal infections. Su et al. have proposed a microemulsion to improve its bioavailability. Their in vivo study indicated that the oral bioavailability of berberine from a microemulsion formulation was $6,47-$ fold higher than that from a berberine nanosuspension [91].

\subsection{Other S(M)EDDS (not marketed)}

In cardiology, numerous drugs have an impact on blood pressure and predictable concentrations are a significant advantage in clinical practice. However, accurate administration of many useful drugs (e.g., nifedipine, nicardipine and atonolol) may require syringe pumps.

Although most of these cardiovascular drugs have sufficient oral bioavailability, some of them are known to be very lipophilic and could be improved via a S(M)EDDS formulation. For example, carvedilol is highly lipophilic and highly protein-bound. It has low solubility in gastrointestinal fluids and undergoes extensive first-pass metabolism in the liver, which leads to a low absolute oral bioavailability of approximately $20 \%$ [92-94]. A S(M)EDDS formulation has been shown to be advantageous: the relative oral bioavailability of a S(M)EDDS formulation compared with commercially available tablets was $413 \%$ [95].

\section{Comparison with other drug delivery systems}

Even though S(M)EDDS are easy to prepare and scale up they should be compared to other formulation. An improvement of the solubility is attainable with fabrication of polymorphs [96], pseudopolymorphs, eutectic mixtures [97], solid dispersions [98], solid solutions [99], polymeric nano- microparticles [100-102], nanosupensions [103], complexation [104], solubilisation by surfactants [6], micronization [105].

Among these methods, polymeric nanoparticles give rise to many publications. For example, nanoparticles of cyclosporine have been proposed compared to Neoral ${ }^{\circledR}$. To date, comparable or increased bioavailability has been achieved by using a series of vehicles including $\mathrm{pH}$-sensitive nanoparticles, [106; 107], poly (lactic acid- 
co-glycolic acid) (PLGA) nanoparticles [108], positively charged chitosan and gelatin nanoparticles [109], solid lipid nanoparticles [110] glyceryl monooleate/poloxamer 407 cubic nanoparticles [111] and nanoparticles made of carboxylated multi-block copolymer of lactic acid and ethylene glycol (EL14) [112].

Besides, other lipids and surfactants based drug delivery systems [6] can also increase the bioavailability of cyclosporin. Examples of applications are polymeric micelles [113], sodium cholate/ lecithin mixed micelles [114], sodium lauryl sulfatedextrin based solid microspheres [115], liposomes [116] and proliposomes [117], solid dispersion containing polyoxyethylene (40) stearate, [118] artificial oil bodies stabilized by caleosin [119] and O/W-emulsion [116].

A simple enhancement of the dissolution of the drug from the vehicles may not lead to increased oral bioavailability. Nanoparticles-gut interactions (e.g. positively charged particles), the dynamic nature of such interactions (e.g. $\mathrm{pH}$ sensitive nanoparticles), the modes of uptake (e.g. lipidic formulations) are very important for further developments.

\section{Conclusion}

The actual applications of S(M)EDDS remain rare. The first drug marketed as a S(M)EDDS was cyclosporin, and it had significantly improved bioavailability compared with the conventional solution. In the last decade, several S(M)EDDS loaded with antiviral drugs (i.e., ritonavir, saquinavir) have been proposed for the treatment of HIV infection.

Forty per cent of newly discovered drug candidates have little or no water solubility and therefore have low and/or erratic variable bioavailability profiles. Many of these drugs are good candidates for formulation into SMEDDS.

\section{Expert opinion}

There are several examples of S(M)EDDS used today as therapeutics (i.e., 
cyclosporin and HIV antiretroviral drugs), and these have provided significant improvements in the pharmacokinetics of lipophilic drugs.

The term "self-emulsifying system" is not clearly mentioned in the summary of product characteristics (SPC), and practitioners only know the products as soft capsules with enhanced pharmacokinetics characteristics. It is therefore difficult to avoid confusion between oily solutions, self-emulsifying systems and other types of lipid formulations.

The formulation of an oily mixture is, in many cases, a very easy and inexpensive process and theoretically can be used for approximately $40 \%$ of new drugs (i.e., insoluble lipophilic drugs). Therefore, it is important to understand why this type of delivery system has not been proposed for many drugs.

The first question that the producer has to answer is: what clinical benefit in terms of pharmacokinetics can be achieved with this type of formulation? For example, the pharmacokinetic profile of cyclosporin is a major problem and can lead to graftversus-host disease. Neoral ${ }^{\circledR}$ was a success; the number of capsules/day was acceptable for the patient, and this formulation improved the pharmacokinetic patterns (i.e., less inter- and intraindividual variability).

The second question is: how many capsules would be reasonable for a standard dosage of the drug? The case of Fortovase ${ }^{\circledR}$ (soft capsules) is interesting because the dosage is 18 capsules/day, and treatment is not very convenient for the patient. The dosage was initially proposed without ritonavir, which is used as a booster, but these drugs now are frequently used together.

Soft capsules of ritonavir have been withdrawn from several countries, primarily due to the requirement for storage between 2 and $8{ }^{\circ} \mathrm{C}$. Tablets can be stored at room temperature, which is convenient for the patient. The similarity with other protease inhibitors (e.g., tipranavir, lopinavir, atazanavir, darunavir) has been considered.

Besides, the development of self-emulsifying systems can be stimulated by obtaining new patent protection.

Various formulation strategies have been reported in the literature and include: incorporation of drugs in oils, solid dispersions, emulsions, liposomes, use of cyclodextrins, co-precipitates, micronisation, nanoparticles, permeation enhancers and lipid solutions. All of these can, to a certain extent, improve the oral absorption 
of drugs. One of the obstacles for the development and comparison of these drug delivery systems is the lack of good predictive in vitro models. Lipid formulations are potentially dependent on digestion prior to release of the drug, and simple dissolution methods are not sufficient to compare lipid formulations with other formulations. In vitro models are somewhat similar to the in vivo process; however, all of these in vitro models require further development to increase the in vitro/in vivo correlation. 
Bibliography Papers of special note have been highlighted as either of interest $(\bullet)$ or of considerable intesrest $(\bullet)$ to readers.

1. Hoar TP, Schulman JH. Transparent water-in-oil dispersions: The oleopathic hydro-micelle. Nature 1943; 152: 102-03

** To our knowledge, this is the first description of microemulsion

2. Schulman J, Stoeckenius W. Mechanism of formation and structure of micro emulsions by electron microscopy. J Phys Chem 1959; 63: 1677-80

3. Danielsson I, Lindman B. The definition of microemulsion. Colloids Surf 1981; 3: 391-92

\section{* This paper gives an important definition of microemulsions}

4. Spernath A, Aserin A. Microemulsions as carriers for drugs and nutraceuticals. Adv Colloid Interface Sci 2006; 128-130: 47-64

5. Shafiq S, Shakeel F, Talegaonkar S, et al. Design and development of oral oil in water ramipril nanoemulsion formulation: In vitro and in vivo assessment. J Biomed Nanotechnol 2007; 3: 28-44

6. Muellertz A, Ogbonna A, Ren S, et al. New perspectives on lipid and surfactant based drug delivery systems for oral delivery of poorly soluble drugs. J Pharm Pharmacol 2010; 62: 1622-36

7. Noh GJ, Lee E-H, Lee SH, et al. Physicochemical properties, pharmacokinetics, and pharmacodynamics of a reformulated microemulsion propofol in rats. Anesthesiology 2008; 109: 436-47 
8. Paolino D, Ventura C, Nisticò S, et al. Lecithin microemulsions for the topical administration of ketoprofen: percutaneous adsorption through human skin and in vivo human skin tolerability. Int J Pharm 2002; 244: 21-31

9. Date AA, Nagarsenker MS. Design and evaluation of self-nanoemulsifying drug delivery systems (SNEDDS) for cefpodoxime proxetil. Int J Pharm 2007; 329: 166-72

10. Pouton CW. Formulation of poorly water-soluble drugs for oral administration: physicochemical and physiological issues and the lipid formulation classification system. Eur J Pharm Sci 2006;

11. Pouton CW. Lipid formulations for oral administration of drugs: non-emulsifying, self-emulsifying and 'self-microemulsifying' drug delivery systems. European Journal of Pharmaceutical Sciences 2000; 11 Suppl 2: S93-8

\section{* This paper describes a simple classification system for lipid formulations}

12. Hu L, Yang J, Liu W, et al. Preparation and evaluation of ibuprofen-loaded microemulsion for improvement of oral bioavailability. Drug Deliv 2011; 18: 90-95

13. Nazar MF, Khan AM, Shah SS. Microemulsion system with improved loading of piroxicam: A study of microstructure. AAPS PharmSciTech 2009; 10: 1286-94

14. Yin Y-M, Cui F-D, Mu C-F, et al. Docetaxel microemulsion for enhanced oral bioavailability: Preparation and in vitro and in vivo evaluation. J Controlled Release 2009; 140: 86-94 
15. Zheng JY, Fulu M-Y. Decrease of genital organ weights and plasma testosterone levels in rats following oral administration of leuprolide microemulsion. Int J Pharm 2006; 307: 209-15

16. Attivi D, Ajana I, Astier A, et al. Development of microemulsion of mitotane for improvement of oral bioavailability. Drug Dev Ind Pharm 2010; 36: 421-27

17. Yang S, Gursoy R, Lambert G, et al. Enhanced oral absorption of paclitaxel in a novel self-microemulsifying drug delivery system with or without concomitant use of P-glycoprotein inhibitors. Pharm Res 2004; 21: 261-70

18. Shafiq S, Shakeel F, Talegaonkar S, et al. Development and bioavailability assessment of ramipril nanoemulsion formulation. Eur J Pharm Biopharm 2007; 66: $227-43$

19. Gupta A. Design and development of microemulsion drug delivery system of nifedipine for improvement of oral bioavailability. Res J Pharm Sci Biotech 2011; 1 : $51-56$

20. Gelderblom H, Verweij J, Nooter K, et al. Cremophor EL: the drawbacks and advantages of vehicle selection for drug formulation. Eur J Cancer 2001; 37: 159098

21. Riehm H, Biedler JL. Potentiation of drug effect by Tween 80 in Chinese hamster cells resistant to actinomycin D and daunomycin. Cancer Research 1972; 32: 1195200 
22. Coon JS, Knudson W, Clodfelter K, et al. Solutol HS 15, nontoxic polyoxyethylene esters of 12-hydroxystearic acid, reverses multidrug resistance. Cancer Res 1991; 51: 897-902

23. Zordan-Nudo T, Ling V, Liu Z, et al. Effects of nonionic detergents on Pglycoprotein drug binding and reversal of multidrug resistance. Cancer Res 1993; 53: 5994-6000

24. Charman SA, Charman WN, Rogge MC, et al. Self-emulsifying drug delivery systems: Formulation and biopharmaceutic evaluation of an investigational lipophilic compound. Pharm Res 1992; 9: 87-93

25. Shah N, Carvajal M, Patel C, et al. Self-emulsifying drug-delivery systems (SEDDS) with polyglycolyzed glycerides for improving in-vitro dissolution and oral absorption of lipophilic drugs. Int J Pharm 1994; 106: 15-23

26. Porter CJH, Charman WN. Uptake of drugs into the intestinal lymphatics after oral administration. Adv Drug Delivery Rev 1997; 25: 71-89

27. Grove M, Mullertz A, Nielsen J, et al. Bioavailability of seocalcitol II: development and characterisation of self-microemulsifying drug delivery systems (SMEDDS) for oral administration containing medium and long chain triglycerides. Eur J Pharm Sci 2006; 28: 233-42

28. Schulman JH, Montagne JB. Formation of microemulsions by aminoalkyl alcohols. Ann N Y Acad Sci 1961; 92: 366-71

29. Aboofazeli R, Patel N, Thomas M, et al. Investigations into the formation and characterization of phospholipid microemulsions .IV. Pseudo-ternary phase- 
diagrams of systems containing water-lecithin-alcohol and oil - the influence of oil. Int J Pharm 1995; 125: 107-16

30. O'Driscoll CM. Lipid-based formulations for intestinal lymphatic delivery. Eur J Pharm Sci 2002; 15: 405-15

\section{* This review analyses the succes and limitations of a formulation approach using lipid-based vehicles and highlights potential areas for further research.}

31. Kang B, Lee J, Chon S, et al. Development of self-microemulsifying drug delivery systems (SMEDDS) for oral bioavailability enhancement of simvastatin in beagle dogs. Int J Pharm 2004; 274: 65-73

32. Lu J-L, Wang J-C, Zhao S-X, et al. Self-microemulsifying drug delivery system (SMEDDS) improves anticancer effect of oral 9-nitrocamptothecin on human cancer xenografts in nude mice. Eur J Pharm Biopharm 2008; 69: 899-907

33. Osipow LI. Transparent emulsions. J Soc Cosmet Chem 1963; 14: 277-85

34. He L, Wang G-L, Zhang Q. An alternative paclitaxel microemulsion formulation: hypersensitivity evaluation and pharmacokinetic profile. Int J Pharm 2003; 250: 4550

35. Patil P, Patil V, Paradkar A. Formulation of a self-emulsifying system for oral delivery of simvastatin: in vitro and in vivo evaluation. Acta pharm 2007; 57: 111-22

36. Prince LM. A theory of aqueous emulsions. I. Negative interfacial tension at the oil/water interface. J Colloid Interface Sci 1967; 23: 165-73 
37. Weiss J. Static and Dynamic Interfacial Tension Analysis. In: Handbook of Food Analytical Chemistry, Water, Proteins, Enzymes, Lipids, and Carbohydrates. Wrolstad RE, Decker EA, Schwartz SJ, et al., Hoboken, New Jersey: WileyInterscience; 2005. p. 631-46

38. Lim H, Lee S, Mo D, et al. Effect of cosurfactant on microemulsion phase behavior in NP7 surfactant system. J Korean Ind Eng Chem 2011; 22: 416-22

39. Bellocq AM, Bourbon D, Lemanceau B, et al. Thermodynamic, interfacial, and structural properties of polyphasic microemulsion systems. J Colloid Interface Sci 1982; 89: 427-40

40. Chen LH, Zhao XT, Wu DZ, et al. Screening the prescription microemulsion by conductivity and the phase behavior. Chin Pharm J 2011; 46: 40-43

41. Brime $B$, Frutos $P$, Bringas $P$, et al. Comparative pharmacokinetics and safety of a novel lyophilized amphotericin B lecithin-based oil-water microemulsion and amphotericin B deoxycholate in animal models. J Antimicrob Chemother 2003; 52: 103-09

42. Gershanik T, Benzeno S, Benita S. Interaction of a self-emulsifying lipid drug delivery system with the everted rat intestinal mucosa as a function of droplet size and surface charge. Pharm Res 1998; 15: 863-69

43. Mandal S. Microemulsion drug delivery system: Design and development for oral bioavailability enhancement of lovastatin. S Afr Pharm J 2011; 78: 44-50

44. Patel V, Kukadiya $H$, Mashru R, et al. Development of microemulsion for solubility enhancement of clopidogrel. Iran J Pharm Res 2010; 9: 327-34 
45. Pal R. Techniques for Measuring the Composition (Oil and Water-Content) of Emulsions - a State-of-the-Art Review. Colloid Surface A 1994; 84: 141-93 ** The review describes various techniques than can be used for the control and characterisation of emulsions

46. Araya $\mathrm{H}$, Tomita M, Hayashi $\mathrm{M}$. The novel formulation design of self-emulsifying drug delivery systems (SEDDS) type O/W microemulsion III: the permeation mechanism of a poorly water soluble drug entrapped O/W microemulsion in rat isolated intestinal membrane by the Ussing chamber method. Drug Metab Pharmacokinet 2006; 21: 45-53

** An important study about the mechanism of absorption of poorly water soluble drugs entrapped in S(M)EDDS. It confirms that the mucin layer participates in the permeability of the drug entrapped in the O/W microemulsion

47. Malenkov AG, Bogatyreva SA, Bozhkova VP, et al. Reversible alterations of the surface of ascites tumour cells induced by a surface-active substance, Tween 60 . Exp Cell Res 1967; 48: 307-18

48. Brossard D, Crauste-Manciet S, Saleh M, et al. Methods for making a formulation and use thereof for administering polar drugs. WO2010/067035 A1 (2010)

49. Han D-H, Jin Z-H, Jin Y-Z, et al. Thermal reversible microemulsion system for poorly water-soluble YH439 for oral delivery. Chem Pharm Bull 2010; 58: 11-15

50. Karasulu H. Microemulsions as novel drug carriers: The formation, stability, applications and toxicity. Exp Opin Drug Delivery 2008; 5: 119-35

* Interesting paper on microemulsions : oral route and other routes (dermal, parenteral, ocular, pulmonary) 
51. Sha X, Yan G, Wu Y, et al. Effect of self-microemulsifying drug delivery systems containing Labrasol on tight junctions in Caco-2 cells. Eur J Pharm Sci 2005; 24: 477-86

52. Masungi C, Mensch J, Van Dijck A, et al. Parallel artificial membrane permeability assay (PAMPA) combined with a 10-day multiscreen Caco-2 cell culture as a tool for assessing new drug candidates. Pharmazie 2008; 63: 194-99

53. Kansy M, Senner F, Gubernator K. Physicochemical high throughput screening: Parallel artificial membrane permeation assay in the description of passive absorption processes. J Med Chem 1998; 41: 1007-10

54. Chen X, Murawski A, Patel K, et al. A novel design of artificial membrane for improving the PAMPA model. Pharm Res 2008; 25: 1511-20

55. Kahan BD. Cyclosporine. New Engl J Med 1989; 321: 1725-38

56. Beveridge T, Gratwohl A, Michot F, et al. Cyclosporin A: Pharmacokinetics after a single dose in man and serum levels after multiple dosing in recipients of allogeneic bone-marrow grafts. Curr Ther Res 1981; 30: 5-18

57. Frey FJ, Horber FF, Frey BM. Trough levels and concentration time curves of cyclosporine in patients undergoing renal transplantation. Clin Pharmacol Ther 1988; 43: $55-62$

58. Ptachcinski RJ, Venkataramanan R, Burckart GJ. Clinical pharmacokinetics of cyclosporin. Clin Pharmacokinet 1986; 11: 107 
59. Mehta MU, Venkataramanan R, Burckart GJ, et al. Effect of bile on cyclosporin absorption in liver transplant patients. Br J Clin Pharmacol 1988; 25: 579-84

60. Venkataramanan R, Burckhart GJ, Ptachcinski RJ. Pharmacokinetics and monitoring of cyclosporine following orthotopic liver transplantation. Semin Liver Dis 1985; 5: 357-68

61. Trull AK, Tan KKC, Tan L, et al. Absorption of cyclosporin from conventional and new microemulsion oral formulations in liver transplant recipients with external biliary diversion. Br J Clin Pharmacol 1995; 39: 627-31

62. Kovarik JM, Mueller EA, Van Bree JB, et al. Reduced inter- and intraindividual variability in cyclosporine pharmacokinetics from a microemulsion formulation. $\mathrm{J}$ Pharm Sci 1994; 83: 444-46

63. Trull AK, Tan KK, Uttridge J, et al. Cyclosporin absorption from microemulsion formulation in liver transplant recipient. Lancet 1993; 341: 433

64. Grevel J, N esch E, Abisch E, et al. Pharmacokinetics of oral cyclosporin a (Sandimmun) in healthy subjects. Eur J Clin Pharmacol 1986; 31: 211-16

65. Drewe J, Meier R, Vonderscher J, et al. Enhancement of the oral absorption of cyclosporin in man. Br J Clin Pharmacol 1992; 34: 60-64

66. Kovarik JM, Mueller EA, Van Bree JB, et al. Within-day consistency in cyclosporine pharmacokinetics from a microemulsion formulation in renal transplant patients. Ther Drug Monit 1994; 16: 232-37 
67. Mueller EA, Kovarik JM, Van Bree JB, et al. Improved dose linearity of cyclosporine pharmacokinetics from a microemulsion formulation. Pharm Res 1994; 11: $301-04$

\section{* This paper describes the improvement in bioavailability and dose linearity of cyclosporine after administration of Sandimmune Neoral.}

68. Griffin BT, O'Driscoll CM. A comparison of intestinal lymphatic transport and systemic bioavailability of saquinavir from three lipid-based formulations in the anaesthetised rat model. J Pharm Pharmacol 2006; 58: 917-25

69. Allard JP, Aghdassi E, Chau J, et al. Effects of vitamin E and C supplementation on oxidative stress and viral load in HIV-infected subjects. Aids 1998; 12: 1653

70. Surjyanarayan M, Snigdha S M, Naazneen S, et al. Design and development of Saquinavir microemulsion for the oral bioavailability enhancement. Int J PharmTech Res 2009; 1: 1442-48

71. Hugen PWH, Burger DM, Koopmans PP, et al. Saquinavir soft-gel capsules (Fortovase) give lower exposure than expected, even after a high-fat breakfast. Pharma World Sci 2002; 24: 83-86

* Description the limitation of saquinavir soft capsules (Fortovase)

72. Fatouros DG, Karpf DM, Nielsen FS, et al. Clinical studies with oral lipid based formulations of poorly soluble compounds. Ther Clin Risk Manage 2007; 3: 591-604 ** An overview of the clinical data available on lipid based formulations.

73. Goddeeris C, Coacci J, Van den Mooter G. Correlation between digestion of the lipid phase of smedds and release of the anti-HIV drug UC 781 and the anti-mycotic drug enilconazole from smedds. Eur J Pharm Biopharm 2007; 66: 173-81 
74. Ghosh PK, Majithiya RJ, Umrethia ML, et al. Design and development of microemulsion drug delivery system of acyclovir for improvement of oral bioavailability. AAPS PharmSciTech 2006; 7: E1-E6

75. Chouksey R, Pandey $H$, Jain AK, et al. Preparation and evaluation of the self emulsufying drug delivery system containing atorvastatin HMG-CoA inhibiter. Int $\mathrm{J}$ Pharm Pharm Sci 2011; 3: 147-52

76. Agüeros M, Ruiz-Gatón L, Vauthier C, et al. Combined hydroxypropyl- $\beta$ cyclodextrin and poly(anhydride) nanoparticles improve the oral permeability of paclitaxel. Eur J Pharm Sci 2009; 38: 405-13

77. Sharma U, Balasubramanian S, Straubinger R. Pharmaceutical and physical properties of paclitaxel (Taxol) complexes with cyclodextrins. J Pharm Sci 1995; 84: 1223-30

78. Perez EA. Novel enhanced delivery taxanes: an update. Semin Oncol 2007; 34: S1-S5

79. King KM, Lupichuk S, Baig L, et al. Optimal use of taxanes in metastatic breast cancer. Journal 2009; 16: 8-20

80. Michaud LB, Valero V, Hortobagyi G. Risks and benefits of taxanes in breast and ovarian cancer. Drug Safety 2000; 23: 401

81. Fanucchi M, Khuri FR. Taxanes in the Treatment of Non-Small Cell Lung Cancer. Treat Resp Med 2006; 5: 181-91 
82. Schrijvers D, Vermorken JB. Taxanes in head and neck cancer. Future Oncol 2005; 1: 829-39

83. Kratz F. Albumin as a drug carrier: Design of prodrugs, drug conjugates and nanoparticles. J Controlled Release 2008; 132: 171-83

84. Khandavilli S, Panchagnula R. Nanoemulsions as versatile formulations for paclitaxel delivery: Peroral and dermal delivery studies in rats. Journal of Investigative Dermatology 2007; 127: 154-62

85. Nichols J, Richardson A. Effects of DDD on steroid response and blood flow through the adrenal after ACTH. Proc Soc Exp Biol Med 1960; 104: 539-42

86. Wallace E, Silverstein J, Villadolid L, et al. Cushing's syndrome due to adrenocortical hyperplasia. Treatment with an inhibitor of adrenocortical secretions. New Engl J Med 1961; 265: 1088-93

87. Attivi D, Gibaud S. Place du mitotane dans la prise en charge du carcinome corticosurrénalien. Act Pharm Hosp 2011; 39-41

88. Batung F, Chajmowics M. Self-microemulsifying mitotane composition. WO 20101136952 (2010)

89. Santos-Magalhaes NS, Pontes A, Pereira VM, et al. Colloidal carriers for benzathine penicillin G: nanoemulsions and nanocapsules. Int J Pharm 2000; 208: 71-80 
90. Heo M, Piao Z, Kim T, et al. Effect of solubilizing and microemulsifying excipients in polyethylene glycol 6000 solid dispersion on enhanced dissolution and bioavailability of ketoconazole. Arch Pharmacal Res 2005; 28: 604-11

91. Gui S-Y, Wu L, Peng DY, et al. Preparation and evaluation of a microemulsion for oral delivery of berberine. Pharmazie 2008; 63: 516-19

92. Chen B, Chow M. Focus on carvedilol: A novel beta-adrenergic blocking agent for the treatment of congestive heart failure. Formulary 1997; 32: 795-\&amp;

93. Morgan T. Clinical pharmacokinetics and pharmacodynamics of carvedilol. Clin Pharmacokinet 1994; 26: 335-46

94. Neugebauer G, Akpan W, von Möllendorff E, et al. Pharmacokinetics and disposition of carvedilol in humans. J Cardiovasc Pharmacol 1987; 10 Suppl 11: S85-8

95. Wei L, Sun P, Nie S, et al. Preparation and evaluation of SEDDS and SMEDDS containing carvedilol. Drug Dev Ind Pharm 2005; 31: 785-94

96. Chinsangaram J, Honeychurch KM, Tyavanagimatt SR, et al. Pharmacokinetic comparison of a single oral dose of polymorph form I versus form $\mathrm{V}$ capsules of the anti-orthopoxvirus compound ST-246(R) in human volunteers. Antimicrob Agents Chemother 2012; [Epub ahead of print] doi: 10.1128/AAC.06090-11

97. Yong CS, Lee M-K, Park Y-J, et al. Enhanced oral bioavailability of ibuprofen in rats by poloxamer gel using poloxamer 188 and menthol. Drug Dev Ind Pharm 2005; 31: 615-22 
98. Saffoon N, Uddin R, Huda NH, et al. Enhancement of Oral Bioavailability and Solid Dispersion: A Review. J App Pharm Sci 2011; 1: 13-20

99. Leuner C, Dressman J. Improving drug solubility for oral delivery using solid dispersions. Eur J Pharm Biopharm 2000; 50: 47-60

100. Ensign LM, Cone R, Hanes J. Oral drug delivery with polymeric nanoparticles: The gastrointestinal mucus barriers. Advanced Drug Delivery Reviews 2012; 64: $557-70$

101. Florence AT. Issues in oral nanoparticle drug carrier uptake and targeting. J Drug Target 2004; 12: 65-70

102. Wong S, Kellaway I, Murdan S. Enhancement of the dissolution rate and oral absorption of a poorly water soluble drug by formation of surfactant-containing microparticles. International Journal of Pharmaceutics 2006; 317: 61-68

103. Müller R, Jacobs C, Kayser $O$. Nanosuspensions as particulate drug formulations in therapy: Rationale for development and what we can expect for the future. Adv Drug Delivery Rev 2001; 47: 3-19

104. Kanwar JR, Long BM, Kanwar RK. The use of cyclodextrins nanoparticles for oral delivery. Curr Med Chem 2011; 18: 2079-85

105. Ning X, Sun J, Han X, et al. Strategies to improve dissolution and oral absorption of glimepiride tablets: solid dispersion versus micronization techniques. Drug Dev Ind Pharm 2011; 37: 727-36 
106. Dai J, Nagai T, Wang X, et al. pH-sensitive nanoparticles for improving the oral bioavailability of cyclosporine A. Int J Pharm 2004; 280: 229-40

107. Wang X, Dai J, Chen Z, et al. Bioavailability and pharmacokinetics of cyclosporine A-loaded $\mathrm{pH}$-sensitive nanoparticles for oral administration. $\mathrm{J}$ Controlled Release 2004; 97: 421-29

108. Italia J, Bhatt D, Bhardwaj V, et al. PLGA nanoparticles for oral delivery of cyclosporine: Nephrotoxicity and pharmacokinetic studies in comparison to Sandimmune Neoral®. Journal of Controlled Release 2007; 119: 197-206

109. El-Shabouri M. Positively charged nanoparticles for improving the oral bioavailability of cyclosporin-A. Int J Pharm 2002; 249: 101-08

110. Müller RH, Runge S, Ravelli V, et al. Oral bioavailability of cyclosporine: Solid lipid nanoparticles (SLN $®$ ) versus drug nanocrystals. International Journal of Pharmaceutics 2006; 317: 82-89

111. Lai J, Lu Y, Yin Z, et al. Pharmacokinetics and enhanced oral bioavailability in beagle dogs of cyclosporine A encapsulated in glyceryl monooleate/poloxamer 407 cubic nanoparticles. International journal of nanomedicine 2010; 5: 13-23

112. Ankola DD, Battisti A, Solaro R, et al. Nanoparticles made of multi-block copolymer of lactic acid and ethylene glycol containing periodic side-chain carboxyl groups for oral delivery of cyclosporine A. Journal of the Royal Society, Interface / the Royal Society 2010; 7 Suppl 4: S475-81 
113. Aliabadi HM, Brocks DR, Lavasanifar A. Polymeric micelles for the solubilization and delivery of cyclosporine A: pharmacokinetics and biodistribution. Biomaterials 2005; 26: 7251-59

114. Guo J, Wu T, Ping Q, et al. Solubilization and pharmacokinetic behaviors of sodium cholate/lecithin-mixed micelles containing cyclosporine A. Drug Deliv 2005; 12: $35-39$

115. Lee $E$, Lee $S$, Choi $H$, et al. Bioavailability of cyclosporin A dispersed in sodium lauryl sulfate-dextrin based solid microspheres. Int J Pharm 2001; 218: 125-31

116. Guo J, Ping Q, Chen Y. Pharmacokinetic behavior of cyclosporin A in rabbits by oral administration of lecithin vesicle and sandimmun neoral. Int J Pharm 2001; 216: $17-21$

117. Shah NM, Parikh J, Namdeo A, et al. Preparation, characterization and in vivo studies of proliposomes containing Cyclosporine A. J Nanosci Nanotechnol 2006; 6: 2967-73

118. Liu C, Wu J, Shi B, et al. Enhancing the bioavailability of cyclosporine a using solid dispersion containing polyoxyethylene (40) stearate. Drug Dev Ind Pharm 2006; 32: $115-23$

119. Chen M, Wang J, Tzen J. Elevating Bioavailability of cyclosporine A via encapsulation in artificial oil bodies stabilized by caleosin. Biotech Progress 2005; 21: $1297-301$ 
Gibaud, S., \& Attivi, D. (2012). Microemulsions for oral administration and their therapeutic applications.

Expert Opinion on Drug Delivery, 9(8), 937-951. doi:10.1517/17425247.2012.694865

Table 1. Main surfactants/co-surfactants, co-solvents and oils used for the preparation of self-emulsifying systems - Example of 6 formulations.

\begin{tabular}{|c|c|c|c|c|c|c|c|c|}
\hline & HLB & Chemical definition & $\begin{array}{c}{[12]} \\
\text { Ibuprofen }\end{array}$ & $\begin{array}{c}{[13]} \\
\text { Piroxicam } \\
\end{array}$ & $\begin{array}{c}{[14]} \\
\text { Docetaxel }\end{array}$ & $\begin{array}{c}{[15]} \\
\text { Leuproreline } \\
\end{array}$ & $\begin{array}{c}{[5 ; 18]} \\
\text { Ramipril }\end{array}$ & $\begin{array}{c}{[19]} \\
\text { Nifedipine } \\
\end{array}$ \\
\hline Tween $^{(\otimes)} 20$ & 16.7 & Polysorbate 20 & & & & & & \\
\hline Tween ${ }^{\oplus} 80$ & 15 & Polysorbate 80 & & $26,5 \%$ & & $40,0 \%$ & & \\
\hline Labrasol $^{\circledR}$ & 14 & Caprylocaproyl polyoxyl-8 glycerides & & & & & & $32,0 \%$ \\
\hline Gelucire $^{(4)} 44 / 14$ & 14 & polyethylene glycol glycerides (Lauroyl macrogol-32 glycerides) & & & & & & ט2, \\
\hline Cremophor $^{\circledR} \mathrm{RH} 40$ & $14-16$ & polyoxyl 40 hydrogenated castor oil & $18,6 \%$ & & & & & \\
\hline Cremophor $^{(\theta)} E L$ & $12-14$ & $\begin{array}{l}\text { polyoxyl } 35 \text { castor oil } \\
\text { d-alpha tocopheryl polvethvlenealycol succinate }\end{array}$ & & & $24,9 \%$ & & $13,5 \%$ & \\
\hline $\begin{array}{l}\text { Vitamine E TPGS } \\
\text { Capryol }^{\circledR} 90\end{array}$ & $\begin{array}{l}13 \\
6\end{array}$ & $\begin{array}{l}\text { d-alpha tocopheryl polyethyleneglycol succinate } \\
\text { Propylene glycol monocaprylate }\end{array}$ & & & $29,4 \%$ & & & \\
\hline $\mathrm{Capmul}^{(1)} \mathrm{MCM}$ & $5.5-6$ & Glyceryl Monocaprylate & & & & & & \\
\hline Capmul PG8 & $5-6$ & Propylene Glycol Monocaprylate & & & & & & \\
\hline Lauroglycol 90 & 5 & Propylene glycol monolaurate & & & & & & \\
\hline Span $^{\otimes} 80$ & 4.3 & Sorbitane monooleate & & & & & & \\
\hline Labrafil $^{\circledR}$ M1944CS & 4 & Oleoyl polyoxyl-6 glycerides & $17,0 \%$ & & & & & \\
\hline Transcutol//®/Carbitol $\left.\right|^{\circledast}$ & 4.2 & Highly purified diethylene glycol monoethyl ether & $9,3 \%$ & & $12,4 \%$ & & $13,5 \%$ & \\
\hline Plurol $^{\circledR}$ diisostearique & $4-5$ & Triglycerol diisostearate & & & & & & \\
\hline Plurol $^{\circledR}$ oleique CC 497 & 6 & Polyglyceryl-3 dioleate & & & & & & $8,0 \%$ \\
\hline Plurol $^{\circledast}$ stearic WL 1009 & $9-10$ & Polyglyceryl-6 Distearate & & & & & & \\
\hline Akoline ${ }^{\circledR}$ MCM & $5-6$ & Mixture of medium chain monoglycerides & & & & & & \\
\hline Maisine $^{(\theta)} 35-1$ & 4 & Glycerol monolinoleate & & & & & & \\
\hline Peceol $^{\circledR}$ & 3 & Glycerol monooleates & & & & & & \\
\hline Labrafac $^{\circledast}$ & 1 & Medium-chain triglycerides & & & & & & $10,0 \%$ \\
\hline Oleic acid & 1 & & & & & $38,0 \%$ & & \\
\hline Sefsol $^{\circledR}-218$ & oil & Propylene Glycol Caprylate & & & & & $20,0 \%$ & \\
\hline Captex $^{(1)} 355$ & oil & Glyceryl Tricaprylate/Tricaprate & & & & & & \\
\hline Sesame oil & oil & Long chain triglycerides & & & & & & \\
\hline Soybean oil & oil & Long chain triglycerides & & & & & & \\
\hline Hydrolysed corn oil & oil & Long chain triglycerides & & & & & & \\
\hline Castor oil & oil & Long chain triglycerides & & $7,5 \%$ & & & & \\
\hline Myvacet $^{\circledR}$ & oil & Distilled acetylated monoglycerides & & & & & & \\
\hline Ethyl oleate & oil & & & & & & & \\
\hline Viscoleo $^{\circledR}$ & oil & Mixture of saturated triglycerides of medium chain length & & & & & & \\
\hline Vitamine $\mathrm{E}$ & oil & & & & & qs & & \\
\hline \multicolumn{9}{|l|}{$\begin{array}{l}\text { Cosolvents } \\
\text { PEG } 400\end{array}$} \\
\hline Ethanol & & & & $55,0 \%$ & & $10,0 \%$ & & \\
\hline Water & & & $55,0 \%$ & $11,0 \%$ & $33,3 \%$ & $2,0 \%$ & $53,0 \%$ & $50,0 \%$ \\
\hline
\end{tabular}


Gibaud, S., \& Attivi, D. (2012). Microemulsions for oral administration and their therapeutic applications.

Expert Opinion on Drug Delivery, 9(8), 937-951. doi:10.1517/17425247.2012.694865

Table 2. Main self-microemulsifying systems marketed in 2012

\begin{tabular}{|c|c|c|c|c|c|}
\hline Brand name & INN & Indications & Dosage & Company & Ingredients \\
\hline \multirow{3}{*}{$\begin{array}{l}\text { Neoral }{ }^{\circledR}, \\
\text { Sandimmun Neoral }^{\circledR} \\
\text { Neoral Sandimmun }^{\circledR}\end{array}$} & \multirow[t]{3}{*}{ Cyclosporin } & & 2 divided doses (BID) & Novartis & \multirow{3}{*}{$\begin{array}{l}\text { Corn oil-mono-di-triglycerides, polyoxyl } 40 \\
\text { hydrogenated castor oil, DL-a- tocopherol, } \\
\text { propylene glycol. }\end{array}$} \\
\hline & & Rheumatoid Arthritis & & & \\
\hline & & Psoriasis & & & \\
\hline \multirow[t]{3}{*}{ Gengraf $^{\circledR}$} & \multirow[t]{3}{*}{ Cyclosporin } & $\begin{array}{l}\text { Kidney, Liver and Heart } \\
\text { Transplantation }\end{array}$ & \multirow[t]{3}{*}{2 divided doses (BID) } & \multirow[t]{3}{*}{ Abbott } & \multirow{3}{*}{$\begin{array}{l}\text { Polyethylene glycol, polyoxyl } 35 \text { castor oil, } \\
\text { polysorbate } 80 \text {, propylene glycol, sorbitan } \\
\text { monooleate. }\end{array}$} \\
\hline & & Rheumatoid Arthritis & & & \\
\hline & & Psoriasis & & & \\
\hline Norvir $^{\circledR}$ & Ritonavir & Treatment of HIV-infection & 2 divided doses (BID) & Abbott & $\begin{array}{l}\text { Butylated hydroxytoluene, ethanol, oleic acid, } \\
\text { polyoxyl } 35 \text { castor oil. }\end{array}$ \\
\hline Fortovase $^{\circledR}$ & Saquinavir & Treatment of HIV-infection & 3 times a day (TID) & Roche & $\begin{array}{l}\text { Medium chain mono- and di-glycerides, } \\
\text { povidone, dl-alpha tocopherol. }\end{array}$ \\
\hline
\end{tabular}


Figure 1. Pseudoternary phase diagram of oil, water and surfactant showing microemulsion region.

Figure 2. Mechanism of intestinal drug transport from lipid-based formulations. The absorption can occur via 4 different mechanisms. Figure adapted from [28], with permission.

The main effect shown includes:
(A) increased membrane fluidity facilitating transcellular absorption,
(B) opening of TJ to allow paracellular transport,
(C) inhibition of P-gp and/or CYP450 to increase intracellular concentration and residence time,
(D) stimulation of lipoprotein/chylomicron production.

In blue: aqueous boundary layer, mucus; TJ, tight junction.

Figure 3. Blood cyclosporin concentration-time curves obtained following single oral doses $\left(10 \mathrm{mg} \mathrm{kg}^{-1}\right)$ of Neoral ${ }^{\circledR}(\mathrm{a})$ and Sandimmun ${ }^{\circledR}$ (b) in eight liver transplant recipients with external biliary diversion. With permission from Wiley [58] .

Figure 4. Pharmacokinetic profiles of saquinavir. SQV-sgc: saquinavir soft-gel capsules. With permission from Springer [68]. 


\section{Surfactant/}

\section{Cosurfactant}

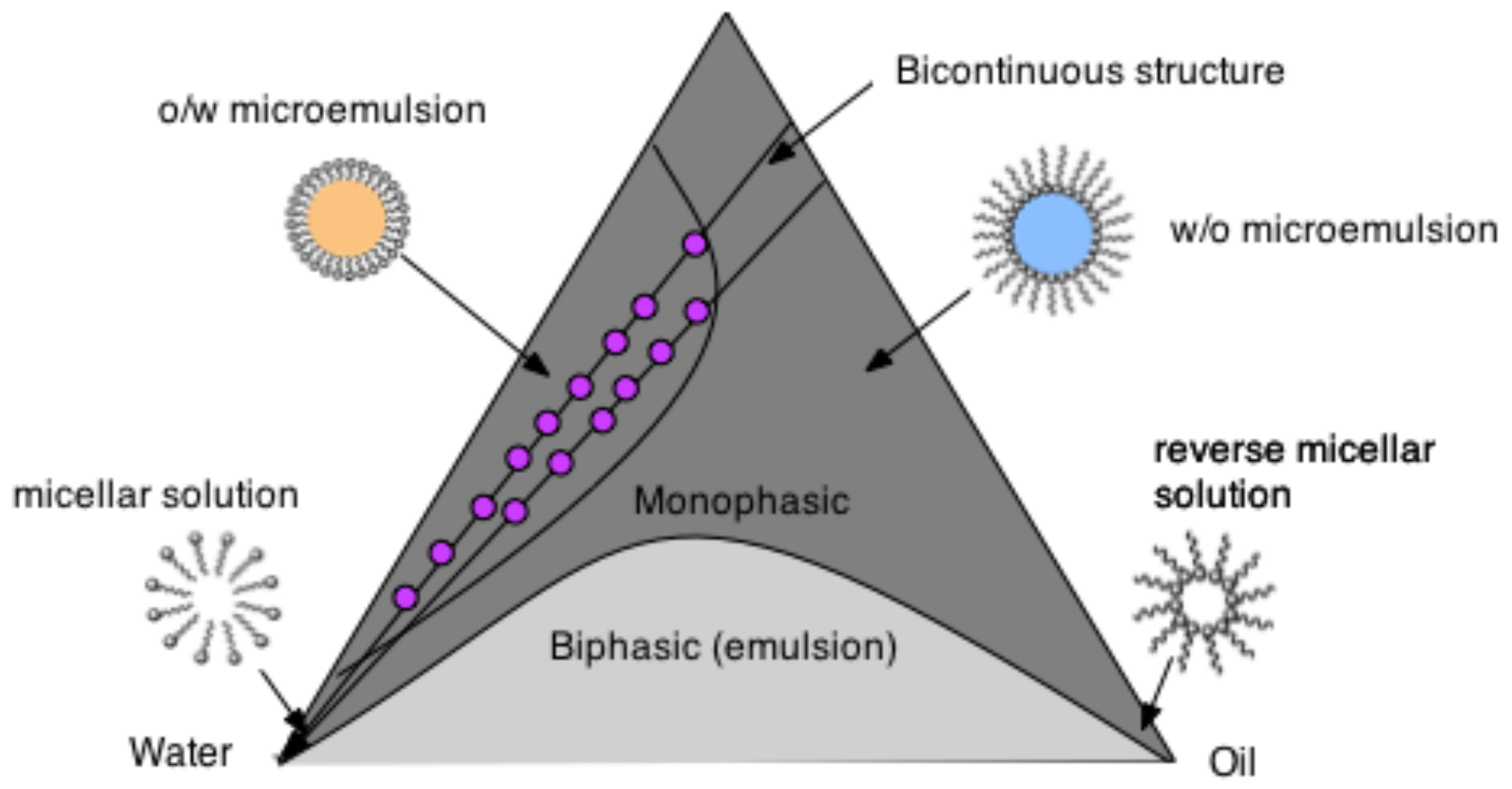




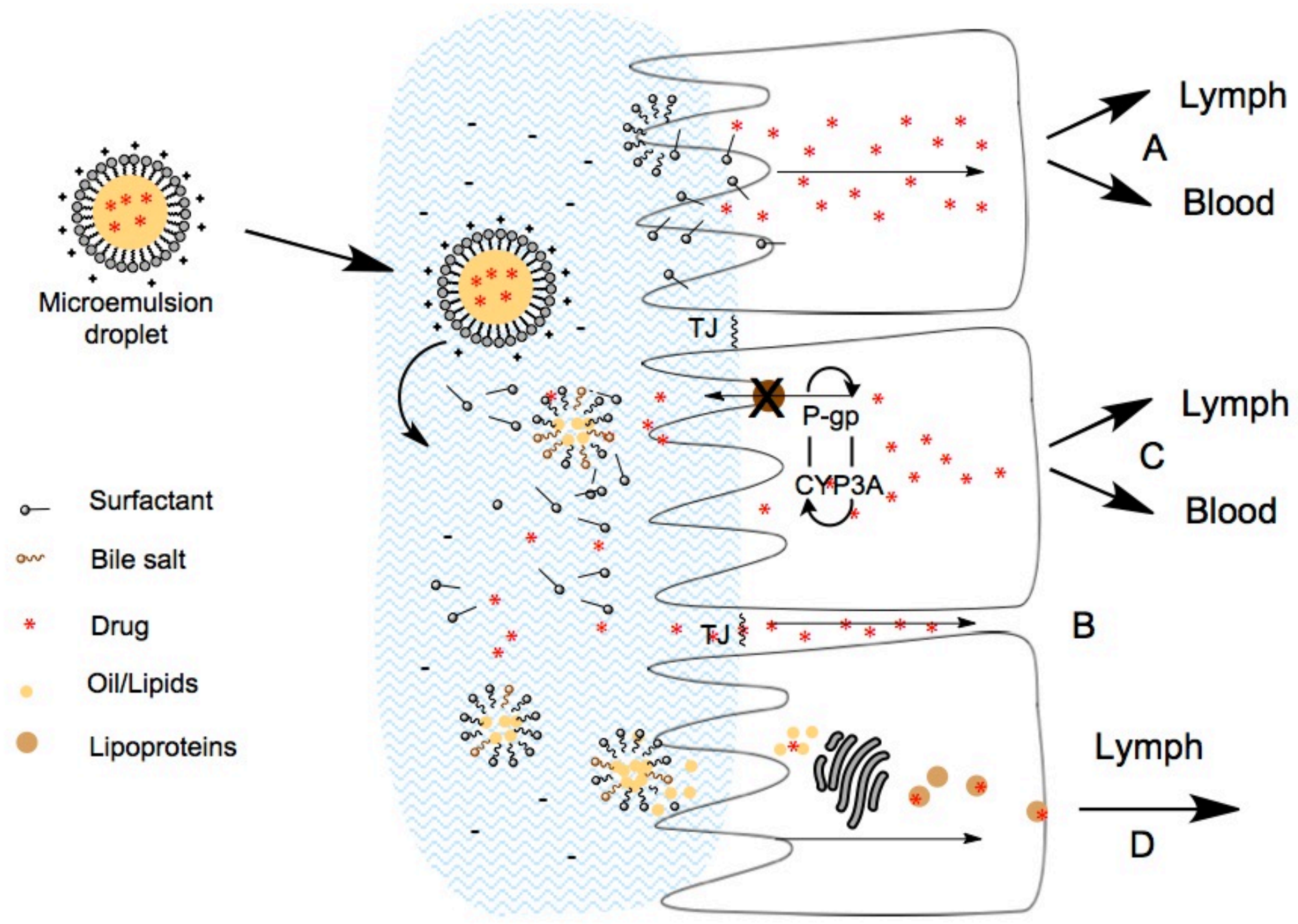


Gibaud, S., \& Attivi, D. (2012). Microemulsions for oral administration and their therapeutic applications.

Expert Opinion on Drug Delivery, 9(8), 937-951. doi:10.1517/17425247.2012.694865

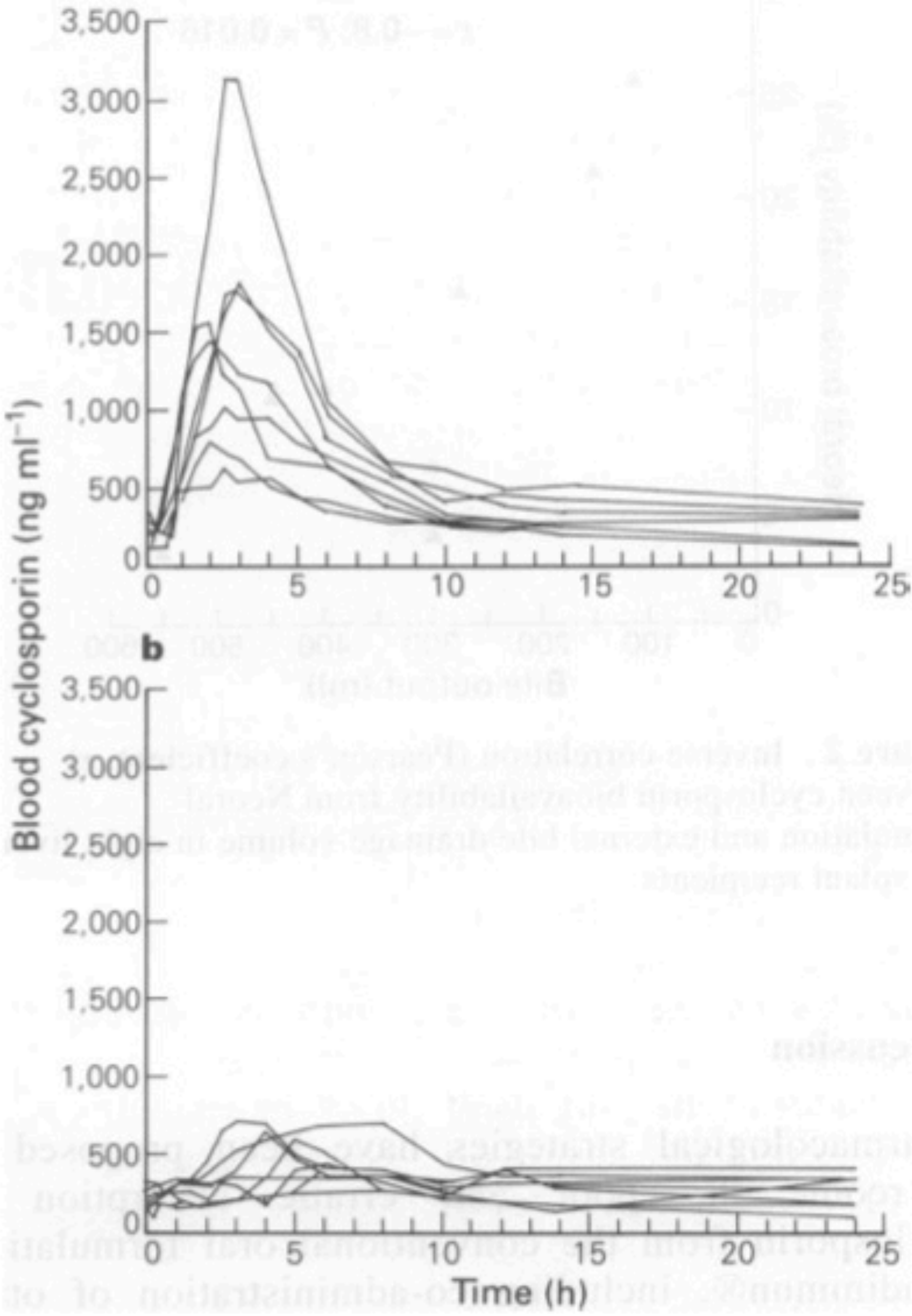


Gibaud, S. \& Attivi, D. (2012). Microemulsions for oral administration and their therapeutic applications.

Expert Opinion on Drug Delivery, 9(8), 937-951. doi:10.1517/17425247.2012.694865

SQV-sgc after normal and high fat breakfast $(n=6)$

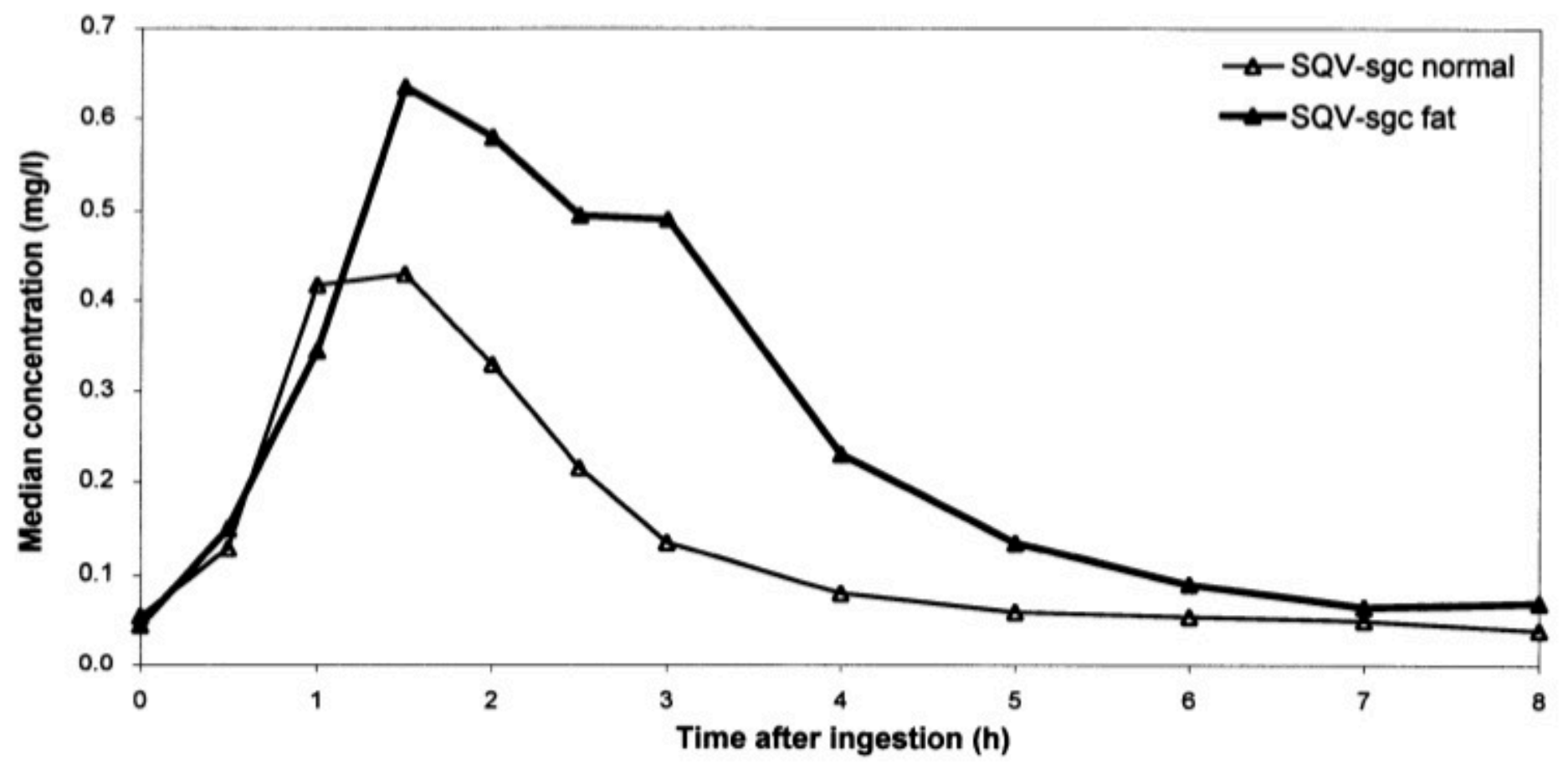

